\title{
Which Words? A Comparison of Learner and Teacher Choices for Lexical Study
}

\section{Michael Guest}

Miyazaki Medical College

Lexical study often sits at the periphery of English lessons and textbooks in Japan, meaning that learners and teachers alike fail to give lexis the attention that it deserves. What this suggests is that learners fail to utilize these fundamental building blocks of the language which could offer widespread benefits to their holistic English development. This limited exploratory study looks at the choices and selection criteria that various groups of learners used to select lexical items from a set text. These are compared with choices and criteria used by teachers, as well as the recommendations of scholars in the field. The author found that not only did choices vary considerably between learners and teachers, but also that these choices often did not correspond to an informed understanding of the nature of lexis.

単語学習は、日本における英語授業や英語学習教材の中では付属的なものと考えられる ことが多い。これは単語学習に払われるべき注意を、学習者・教師の双方が怠っているこ とを意味している。これはまた、学習者が、英語学習全般に大きくかかわっている単語と いう言語の構成部品を十分に利用できないでいることを示している。

本論文では、限定的ではあるが、英語学習者が英文から単語を選び出す際に、何に注目 して選定を行うのかを考察した研究を報告する。学習者が行った単語の選定方法は、教師 が行った単語の選定方法、研究者が報告した選定方法と比較して考察を行った。その結 果、教師と学習者では単語の選定方法が異なるだけでなく、いずれの選定方法も、単語の 本質についてこれまでに報告されている内容と必ずしも合致しないことが判明した。

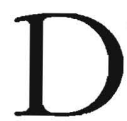

espite the increased advocacy of a "lexical syllabus" or a "lexical approach" to English language learning in recent years, many textbooks and lesson plans in Japan still appear to give lexical studies only peripheral status (Fukuda, 1994) in favor of the much narrower concept of "vocabulary." While lexical studies take into account the syntagmatic, collocational and other environmental qualities of an item (which may well be a set phrase, polyword or any self-contained unit of meaning), "vocabulary" tends to be limited to single words and their paradigmatic meanings (Carter, 1987; Sinclair, 1991). Moreover, 
those single-word items that have concise, dense, limited meanings tend to make up a relatively small amount of both written and spoken English text, according to corpus-based studies (Sinclair, 1991; Quirk, Greenbaum, Leech, \& Svartvik, 1985; Swan, 1995). Halliday and Hasan's (1976) and Halliday's (1990) delineation of the ideational, interpersonal, and textual functions of language indicate that while the latter two functions are heavily represented in texts, much classroom vocabulary teaching tends to focus inordinately upon the former (Carter, 1987). Indepth research into specific lexico-grammatical items like that of Francis (1985) and Schiffrin (1987) underscores the crucial role that interpersonal and textual items play in spoken discourse in particular. Nattinger and DeCarrico (1992) and Sinclair (1991) have all long argued that mastery of delexicalized items and high-frequency, high-valency, wide-range, syntagmically significant polywords that make up such a large part of English is a key to the mastery of the language on a holistic scale. Lewis (1993) and Willis (1990) strongly advocate syllabi that key upon such lexico-grammatical "chunks" as basic analytical units for language learning.

Yet in many English lessons in Japan, according to Fukuda (1994), the potential richness of lexical study is often reduced to mere scraps of "vocabulary." Fukuda notes that this tends to appear in most lessons via two primary paradigms, neither of which treat lexis as an object worthy of study or analysis in its own right.

The first paradigm is that of a decoding system, which employs vocabulary study primarily as an aid for successful negotiation of the text that is before the learners. This usually consists of the teacher making a list of vocabulary items for pre-teaching or fielding learners' questions about "difficult" items while learners are doing the task. A translation or explanation is then provided and is presumed to help the learners to "get through" or decode the text, allowing the learners to complete the more "pertinent" tasks more efficiently.

This paradigm represents a concession to Nunan's (1989) argument that both learners and teachers should be more concerned with interacting with a text and completing the tasks related to it than with the analysis of its constituents. It is argued that "constituent analysis" often obscures the learners' search for meaning and inhibits absorption of the communicative function of a text. Thus, users of this paradigm may tend to overlook the import of lexical analysis, which involves the atomizing of text constituents, fearing that it may interfere with comprehension of the more general or holistic meaning.

The second paradigm noted by Fukuda (1994) encourages learners to make and keep vocabulary notebooks based on the new items they 
have encountered in classroom texts (along with, perhaps, a translation or small notation). This paradigm, which may be appended to the first, adds an encoding element to the study. This usually consists of students amassing encyclopedic lists of invariably "new" items that have arisen from the text, generally after the "main" tasks of the lesson have been completed.

According to Fukuda's (1994) study, teachers often allow some classroom time for this activity but little supervision or guidance is given in the process of item choice or the content of the accompanying notation. In most cases, the nature of these notations and their future uses are not made clear, as vocabulary's place in the syllabus seems to be little more than that of a taxonomy or appendix. Often these two concessions to "vocabulary" learning constitute the entire lexical element of a syllabus.

Fukuda (1994) notes that this approach is often defended by teachers on the basis of the belief that interference with the learners' choices ignores the inner agenda of the learner and inhibits autonomous learning, a viewpoint often attributed to Swain (1995). In a learner-autonomy paradigm, there is a tendency to view teacher-centeredness as anachronistic and (wrongly) associated with the prescriptivism of grammar-translation methodologies. I should note here that although neither Nunan (1989) nor Swain (1995) themselves appear to explicitly disapprove of a deliberate, teacher-guided focus upon lexical constituents of a text, their respective emphases appear to have influenced many teachers in adopting such methodological positions (Fukuda, 1994).

However, in this paper, I intend to show that if we are to take lexis seriously and put it in the forefront of our syllabus where advocates of a lexical syllabus such as Carter (1987), Lewis (1993), and Willis (1990) argue that it deserves to be, a teacher-centered, stipulative approach will most benefit learners in making wise, useful choices for lexical study and choices for analysis. This will, in fact, aid in increasing comprehension of general meanings because (1) a certain degree of initial teacher-centeredness can allow for a higher quality of eventual learner autonomy, and (2) the analysis of lexical constituents in fact allows learners to more fully apprehend meaning beyond the merely ideational. I will also argue that teachers themselves will often require a greater awareness of the characteristics of lexis before they can meaningfully impart such skills to their students.

Evidence for this conclusion comes from a limited exploratory study I conducted in which learners' lexical choices from a short text were quantified and then compared (quantitatively and qualitatively) with teachers' choices. The resulting disparity between the two groups' choices, compared further to lexical scholars' analysis of these lexical 
items, indicates (1) it is better not to leave learners up to their own devices when analyzing lexis and making choices for future study of these items, and (2) that teachers themselves often neglect to note certain central qualities of lexis.

\section{Research Focus}

For a long time as a teacher I had strictly obeyed the pedagogical dicta of practicing student autonomy and giving priority to meaning over form. As a result, I had left vocabulary study choices to the vagaries of each student's needs and wishes without any interference on my part. But having regularly noted my students making questionable choices in regard to items listed in their vocabulary as well as demonstrating a clear lack of awareness of lexical patterning, I gradually became aware that my concept of student autonomy was akin to teacher negligence. Therefore, I conducted a short exploratory in-class study to reveal the nature of learners' selections of lexical/vocabulary items and to learn what focuses and prejudices students entertained about English lexis. I was also curious as to how these compared to teachers' selections. If different criteria were being employed by teachers and students, what were they and why? The results of these inquiries follow. After presenting and analyzing the results, I then compare learners' and teachers' selections with what scholars of lexis have to say on the subject.

\section{Method}

The study was performed and analyzed over six months of 1998. A short text was taken from a script from the NBC medical drama, E.R. This text was chosen precisely because it is so rich in its variety of lexical items. The following text was used:

Well, I would have gotten over it sooner, but damn it, then this, this ... what's it called... this coniosporosis just went and made things worse.

\section{Subjects}

Three groups of subjects were used:

1. 97 second-year university medical students, currently taking required English courses. None were English majors and skill levels varied greatly. 
2. 96 second-year English majors at a different university, most with upper intermediate or advanced English skills.

3. 25 English teachers (eight Japanese and seventeen non-Japanese) teaching at colleges and universities in Japan. The teachers were former colleagues and associates of mine and represented a variety of age groups, nationalities, qualifications, teaching experience, and knowledge of Japanese learners of English. All were teaching general, nonspecific/professional English to intermediate or upper intermediate Japanese learners of English. This teacher sample was completed by e-mail.

Two intact classes were used for this study as a sample of convenience. Both classes contained a variety of attainment levels and study habits, a balance of males to females and a slightly wider age range (19 to 30) than normally expected in a Japanese university. The inclusion of a sample group from a medical school could have implications for a discussion of ESP but is beyond the immediate scope of this study.

\section{Procedures}

The two learner groups were asked to complete the task with myself as monitor. All instruction was also translated by a colleague into Japanese to minimize faulty understandings of the task and its contents. In presenting learners with the text on a slip of paper, I provided the learners with following information and instructions:

The following line comes from a TV show. The speaker is a middleaged man who is in hospital with a serious sickness. He is speaking to other members of his family. After reading the line, choose five items from it that you think would be most useful for your general English study in the future; that is, items that you'd likely include in your language learning notebooks. The items don't have to be single words. They may be phrases, phrasal verbs, grammar points, word combinations, social features or anything else that you think is important or useful for the improvement of your general English skills.

Before the subjects made their selections, my Japanese colleague and I explained the meaning of the text both in general and item-specific terms, until all subjects indicated that they had sufficiently understood it. I strongly emphasized that the learners should focus upon choosing items for "future" and "general" English learning, rather than for comprehension of the sample text alone. The learners were then asked to each choose their five items. All responses were written under the text on individual slips of paper which were then collected. Learners did not identify themselves by name on the slip of paper. They were also asked, but not required, to write the reasons for their choices. 
Separately, the twenty-five English teachers were asked which five items from the text they would highlight for teaching purposes or have their learners highlight for general skills or future study. All were asked to make their choices with their own classes in mind. The same explanation as that given to the learners was sent by e-mail to teacher subjects (substituting "your students" where appropriate). As with the learner samples, teachers were also asked to provide reasons for their choices. No subjects were made aware of the objective of this study.

\section{Results \\ Lexical Analysis of the Text}

Before we look at the results of the subjects' choices, let us first analyze some of the more pertinent lexical features that arise within the text. No singular method of analysis was used here as the various items within the text hold differing properties that are best explicated by a variety of analytical methods. Much of my analysis is informed by the lexical scholarship of Carter (1987) who argues that:

The structural semantic and relational properties of lexical words ... and of some words having greater lexicality than others is of considerable potential relevance and interest for studies with an applied linguistic perspective. (pp. 28-29)

I have previously noted the centrality of the connotative and syntagmatic properties of items keeping in mind Carter's (1987) suggestion that:

It is dangerous to pursue the meaning of a word by exclusive reference to what it denotes; stylistic and associative meanings are often as significant ... an analysis of words which remains at the level of the word ... and does not consider the role and function of words within larger linguistic and contextual units will be inadequate. (pp. 28-29)

Also employed here are the results of the corpus-based studies of Sinclair (1991) which indicate not only item frequency but the notable valency of lexically light items, concluding that:

Learners would do well to learn the common words of the language very thoroughly, because they carry the main patterns of the language. (p. 79)

Much of this analysis is also influenced by the "chunking" methodology of Lewis (1993) who identified lexical items as having the following three properties:

1) Meaning is not totally predictable from form. 2) Each is a minimal unit for certain syntactical purposes. 3) Each is a social institution (p. 89). 
Related analytical tools used include noting set polyword units, the "prefabricated patterns" of Nattinger and DeCarrico (1992) who state:

Research in computational analysis of language . . confirms the significance of patterned phrases as basic, intermediary units between the levels of lexis and grammar (p. 23).

Nattinger and DeCarrico (1992) regard these lexical patterns as central to the development of pragmatic competence. Thus, for certain items, the pragmatic and sociolinguistic forces of lexis as explicated in the discourse analysis scholarship of Schiffrin (1987), Fasold (1990) and Francis (1985) are utilized. For others, the lexico-grammatical qualities that affect syntax as noted in comprehensive grammars such as those of Quirk, Greenbaum, Leech, and Svartvik (1985) and Swan (1995) are applied, as well as the three discourse-defining metafunctions noted by Halliday and Hasan (1976).

Let us proceed in the order in which the items appear in the text:

1.Well: This is a delexicalized word (it has a use or function rather than a meaning) and as such, has a very high frequency (Quirk et al., 1985; Sinclair, 1991). It thus holds high recognition value among learners. Used here as a discourse marker, it has a very clear textual function as it is primarily used to signal an explanation (Fasold, 1990). It also has a clear interpersonal function, as it is often used to signal an alternate response that the original interlocutor is perhaps not expecting to hear or that is different from that which the interlocutor has implied (Schiffrin, 1987). It can thus take on both softening or intensifying functions. Traditionally, such items have been treated as grammatical, not lexical, units (Lewis, 1993; Carter, 1987).

2. Would have ... en: A quintessential example of a lexical "chunk" that straddles lexico-grammatical boundaries (Willis, 1990), "would" has extremely high frequency (Sinclair, 1991) and the "have + en" collocation in particular is a major feature in all registers and genres of English. Because of its grammatical properties, it is lexically light; that is, it does not offer up an immediate meaning to the learner (Willis, 1990). Constructing the combined unreal/perfective aspect, and knowing when to apply it, is notoriously difficult for Japanese learners of English.

3. get/got/gotten: The wide lexical range (meaning potentials) of "get" also makes this a very high frequency item (Sinclair, 1991; Carter, 1987). It has high recognition value amongst learners who tend to ascribe to it a prototypical (core) meaning akin to "receive." 
However, its high degree of valency (ability to combine with a variety of linguistic environments), along with its heavy polysemy (variety of meaning potentials) (Swan, 1995), may indicate that familiarity with a prototypical sense alone is unlikely to imply a complete or even adequate understanding of such an item (Lewis, 1993).

4. get over - : This is a fairly high-frequency phrasal verb and, as with many phrasal verbs, it is more frequent in low register or casual speech (Carter, 1987). Again, there is a variety of meanings but all carry a strong degree of lexical density (i.e., they correspond to a clear, discrete concept or idea).

5. it: This is an anaphoric (referring to an item previously made explicit) discourse marker serving a textual cohesion function (Francis, 1985).

6. damn it: This is an expletive, expressive "social" phrase which clearly indicates the speaker's attitude towards the matter at hand. It does not show a particularly high frequency in speaking and may be more closely related to idiolect (personal "style"). Register and genre are key factors in its usage.

7. this, this ... this: This is also a cohesive discourse marker (in this case cataphoric, looking forward to a reference), but perhaps more noteworthy as a "chunk" is the repetition of the item. As such, it has a pre-sequencing function which indicates the speaker's lack of familiarity (perhaps disgust) with, or confidence in, using the term that follows ("coniosporosis").

8. what's it called: A common self-repair strategy, here manifested as a complete lexical phrase, (Nattinger and DeCarrico [1992] would classify it as a "deictic locution") that usually precedes an item that one is attempting to name. It reinforces the lack of assuredness regarding the term to follow and is notable for its collocation here with "this, this . . . this" (see \#7 above). Such formulaic chunks are now considered to be at the very center of the language acquisition process (Nattinger and DeCarrico, 1992).

9. coniosporosis: A very lexically dense, extremely low frequency item with a very professional register, related almost exclusively to the medical discourse community. Such lexically dense items are far more typical of written English (Halliday, 1990). (Coniosporosis is a condition in which a combination of asthmatic and acute pneumonic complications occurs after one ingests a particular treebased fungus. It does not appear to be widely known even among 
native speakers in the medical community.)

10. just: Like "get," "just" is an extremely high-frequency, widerange item which has much higher frequency in spoken than written English (Carter, 1987). Also like "get," its prototypical meaning ("only") often does not aid in the interpretation of many of its usages. It often performs an interpersonal function, that of intensifying or emphasizing an utterance (Swan, 1995), quite at odds with its core meaning. Repeated use may mark it as idiolect.

11. went and/go and: A fairly high-frequency chunk, nearly uncategorizable by traditional grammatical standards (describing it simply as a lexical phrase serving a discourse marking function may be most accurate). It has generally low register usage, is extremely light lexically, and is usually found in explanations or narrative genres, particularly in the spoken language. It appears to reflect idiolectic tendencies and is largely a North American variety, adding interpersonal flavor to an utterance by appending a negative, judgmental force (often meant to convey a sense of unfairness or disgust).

12. make ... worse: A moderately high frequency lexical phrase, having a variable relationship with other comparative adjectives (an example of Nattinger and DeCarrico's [1992] "phrasal constraints"). Learners are often fairly knowledgeable of and accurate in using each word within the phrase but often do not know it as a set phrase, even though in this case the meaning is deducible by merely combining the individual items within the phrase. As with many lexical phrases, learners tend to know the higher-register but lower frequency related terms such as "weaken" or "ruin," precisely because these are lexically dense dictionary headwords.

13. things: This is used here as a "general word," and, as such, is a high-frequency item particularly in real-time speech when one is unable to recall a more exact, but perhaps obscure, lexically dense item. It thus serves as a circumlocutionary strategy when searching for a more precise description or word. As intentionally "vague language" (Carter, 1987), it is lexically lighter than may be initially intuited. It has a wide range of uses, particularly where the norms of discourse would render the more precise word as awkward or marked (Halliday \& Hasan, 1976). 


\section{Student and Teacher Responses}

The numbers of items in some of the samples do not total the expected five responses per student for the following reasons:

1. Some students submitted anywhere from two to seven selections rather than the requested five. Where more than five selections were given, only the first five listed were counted.

2. Some selections were clearly longer or shorter than any meaningful lexical category and were thus disqualified (e.g., "then this coniosporosis").

3. In some cases, the focus of the selection was not clear (e.g., Does "would have gotten" qualify as "would have -en" or as "get/got"?). In such cases of boundary vagueness, a half point was "awarded" to each item.

\section{Medical Students}

As perhaps would be expected, the medical students largely chose lexically dense ideationally based items (those items that appear to offer a meaning that is discrete and corresponds to a clear, content-heavy concept or thing) (see Table 1). The popularity of "get over," "make worse," and "coniosporosis" (75, 70, and 72 selections, respectively) was often related to their perceived utility in the medical field, suggested by numerous comments such as, "This is useful for my future as a doctor."

Table 1: Lexical Selections by Medical Students $(n=97)$

\begin{tabular}{lrlrlr}
\hline Item & No. & Item & No. & Item & No. \\
Well, & 10 & would (have -en) & 42 & get/got/gotten & 13 \\
get over & 75 & it & 3 & damn it & 77 \\
this, this . . . this & 5 & what's it called & 19 & coniosporosis & 72 \\
just & 5 & went and/go and & 5 & make - worse & 70 \\
things & 10 & sooner & 13 & then & 3 \\
\hline
\end{tabular}

As shown in Table 1, the major exception to this tendency was "damn $i t$, " the item that received the highest overall number of selections (77). It is interesting that this one interpersonal item received more selections than the more concrete lexical phrases. The fact that "damn it" was justified with reasons such as, "I didn't know this word" (as was "coniosporosis"), indicates that sheer lack of recognition is a salient selection criterion for learners. On the other hand, although "Well" is also an interpersonally 
based item, it received little support (10). "Well," despite being more frequent and having a more pronounced discourse function than "damn it," may have been ignored largely because students simply recognized the item and believed that recognizing an item equals knowing it, a common misunderstanding.

The same may also be argued for a lexically light item such as "just" (5). However, most such high-recognition but low-density, high-frequency/valency items were overlooked by these students. The fact that such items make up the great bulk of English speech (Carter, 1987; Sinclair 1991; Richards, 1974) and act as the workhorses of the language, and that mastery of these items can lead to greater general control in the production of English seems not yet apparent to them.

Returning to those lexically dense items that garnered the most selections, one might expect that after the teacher's explanation, "coniosporosis" would have been rightly regarded as arcane terminology with very limited utility and range. But the large number of selections (72) for this item suggests that learners' criteria for selection may be based more upon encyclopedic or taxonomic factors than upon concerns of utility or range. One can speculate from this that ESP students may be attempting to acquire specialized jargon far in advance of having developed a holistic L2 system in which to place that jargon, despite the fact that Arnaud and Savignon (1997) argue that rare words are best learned passively by more advanced speakers, not by a taxonomic list method.

However, a number of students did select "what's it called" and "would ..." (19 and 42, respectively), one a set phrase, the other a lexically light function word. One possible explanation, borne out by the reasons that students offered for their choices, was the understanding that these items matched difficult L1 concepts that they had hitherto struggled with. For example, regarding "would" one student wrote, "This word shows possibility and difference from real situation. It says like Japanese naotta no ni. I didn't know to say like that in English." Many recognized a different utility from what they had previously noted. Regarding "what's it called" a student wrote, "If I can't remember name or the word, I can say this in the middle of my sentence. It's like Japanese. We say same things like this."

This reaction may have occurred because the monitor's explicit explanation allowed the subjects to find a useful L1 conceptual frame to peg the item upon. From this example we can see how much more essential an explicit identification of an item's role in the text is to making more informed choices than would be the case if the learners were simply listing "unknown" items from a decontextualized, unanalyzed text. 


\section{English Majors}

Let's first analyze these results in terms of their similarities to and differences from the information collated from the medical students' selections.

"Get over" and "damn it" still received a large number of selections (63 and 69, as shown in Table 2) and it seems that for these items the same criterion was applied as by the medical students; that is, that they are easily translatable, readily offering up L1 parallels. Again, many students responded to the effect that "not knowing" the item was the main criterion behind the selection. In other words, most learners appear to see lexical study as a means of decoding (unraveling the meaning of an item) rather than encoding (absorbing more general principles of lexis for future deployment).

Table 2: Lexical Selections by English Majors $(n=96)$

\begin{tabular}{lcllll}
\hline Item & No. & Item & No. & Item & No. \\
\hline Well, & 5 & would have - r & 67 & get/got/gotten & 12 \\
get over & 63 & it & 3 & damn it & 69 \\
this, this . . . this & 28 & what's it called & 44 & coniosporosis & 49 \\
just & 10 & went and/go and & 26 & make - worse & 46 \\
things & 9 & sooner & 16 & then & 1 \\
\hline
\end{tabular}

I should also add that the anomalous popularity of "damn it" (69) appears to stem somewhat from an almost abnormal interest among the learners in learning profanities. One student noted, "This is real English, like native speakers speak." This comment suggests that a perceived difference between "real" English and more stilted, limited forms that they may have studied in the past is largely characterized by profanities. This is a potentially dangerous misconception that needs to be addressed.

Notable differences occurred with, "this, this ... this" and "just, " both of which showed marked increases over the number of selections made by the medical students (from 5 to 28 and 5 to 10 respectively). This indicates that English majors are perhaps (not surprisingly) somewhat more aware of their general lexical needs, precisely because they are not studying for a specific purpose. As they need not focus so heavily on acquiring jargon as medical students do, English majors appear to be more attracted by language that contains many meaning potentials. Regarding "just," one comment was, "This word has many meanings and I don't know why a native speaker says it so much." Regarding "this, this . . this," another student wrote, "I can show a confusion feeling when I repeat that word." 
Students also recognized that some phrases impart grammatical functions. For example, regarding "would bave," one student wrote, "I know this phrase means, but I can't use it well, so I must study it more." In short, the English majors appeared to display slightly more sophisticated metalinguistic insights in their selection criteria although the surprisingly heavy number of selections for "coniosporosis" (49) certainly must mitigate the force of this suggestion. One notable difference between the medical students and the English majors regarding the number of selections for "went and/go and" (from 5 to 26) is worthy of comment. The teacher who monitored the English majors during the study noted that a specific question regarding this item was raised by a student. This allowed the teacher to provide an interpretation of this item which may have lead this group to become unusually conscious of the item. Thus, after hearing the explanation and realizing that this item contained a force that was quite different from what they might previously have believed, the number of selections for this item increased considerably. One student commented, "I learned that this does not mean 'go out' . . . it shows a helpless feeling of the people." Thus, we may note that explicit explanation of an item can lead to its critical reevaluation by students.

\section{English Teachers}

Despite the disparity in sample size, it is no less evident that teachers' choices differed greatly from those of both samples of learners, as shown in Table 3.

Table 3: Lexical Selections by English Teachers $(n=25)$

\begin{tabular}{lrlrlr}
\hline Item & No. & Item & No. & Item & No. \\
\hline Well, & 4 & would (have -en) & 14 & get/got/gotten & 6 \\
get over & 23 & it & 13 & damn it & 10 \\
this, this . . . this & 8 & what's it called & 4 & coniosporosis & 1 \\
just & 4 & went and/go and & 0 & make - worse & 19 \\
things & 1 & sooner & 2 & then & 6 \\
\hline
\end{tabular}

Not unsurprisingly "damn it" and "coniosporosis" dropped in number from 77 and 69 to 10, and from 72 and 49 to 1 respectively. Of course, teachers are expected to display a greater sense of the range and utility of items than do students (particularly as we have seen with non-English majors). This was apparent in that "get over" and "make ... worse" and 
the lexico-grammatical "would have ... en" were deemed to be far more useful (92, 76 and 14 respectively) than "damn it" and "coniosporosis."

While many teachers emphasized the necessity of focusing upon phrasal verbs ("They are often not found in the dictionary and students are unaware of them even though they are used regularly by native speakers"), it was notable that other lexical phrases or polywords ("What's it called," "went and") were largely ignored ( 4 and 0 respectively). Here, like the medical students, teachers seem to have placed more emphasis upon lexically dense, content-based items rather than those items characterized by discursive or interpersonal features. It is particularly noteworthy that English majors seemed to consider the latter items to be more valuable than did teachers. Perhaps these are items that teachers expect students to already "know" based on the recognition value of their individual constituents, whereas the English majors, cognizant of their own struggles with such items and their difficulties in finding a cognate in L1, perceived them as unlearned but useful.

A slight increase in the number of teacher selections compared to learner selections was found for the deictic items (those which make test cohesive by pointing to references), that is, "this, this ... this," (only for medical students) "it" and "then" (students: 5 and 28, teachers: 8; students: 3 and 3, teachers: 13; and students: 3 and 1, teachers: 6 , respectively). The criteria for selecting such items appeared to have been very precise, as the following teacher explanations indicate:

Students cannot fully understand how to read, write or speak English properly until they can use these words well.

Such terms are the cohesive skeleton of any text and thus cannot afford to be ignored.

Nonetheless, nondeictic high frequency items that add an interpersonal dimension to the text by serving as pre-sequencers ("Well"), softeners/ intensifiers ("just"), or by marking attitudes ("went and") were roundly ignored (4, 4 and 0 respectively) as was the common general word "things" (1) despite its deictic function. Again, one may speculate that this is because teachers believe that students already "know" these "basic" items. However, such a presupposition would be faulty given the wide meaning range and potentials that these items display.

\section{Discussion}

Although this study is limited and exploratory, the results suggest that learners often do not make lexical study choices based upon sound principles. We have seen that learners tend to focus upon lexically dense, 
ideationally based items that offer up more exacting, content-heavy meanings that can be readily decoded. This is in accordance with McCarthy and Carter's (1995) findings. McCarthy (1991) further notes that learners often wrongly equate fixed meanings with fixed lexical patterns in a text. And if one adheres to Pawley and Syder's (1983, p. 203) definition of lexis, as an item in which meaning is not predictable from form, one can fairly conclude that learners tend to choose "vocabulary" rather than lexical items.

However, corpus studies indicate that the type-token ratio of lexically light items is much greater than that of content-heavy dense items and therefore much more crucial to an understanding of discourse (Sinclair, 1991; Richards, 1974). Moreover, lexical density is more a feature of written than of spoken texts (Ure, 1971; Halliday, 1990). Thus, this inordinate emphasis upon lexically dense items may be one reason why learners are apt to speak as if they were walking textbooks (Carter \& McCarthy, 1994).

Simply not knowing a word (and one can assume that "knowledge" in this case is closer to "recognition" in meaning) was the most common explanation for such choices. Scholars such as Carter (1987) have drawn up hierarchical criteria of lexical "knowledge," with recognition representing its lowest level. This hierarchy progresses through knowledge of an item's syntagmatic(environmental), paradigmatic (syntactically substitutable), and pragmatic qualities and to the ability to produce, as well as comprehend, the item within idiomatic forms. The fact that learners seem to be satisfied with knowing an item only in its most superficial sense indicates that current approaches to acquiring lexis need to be redressed.

We have also noted that those items which teachers tend to emphasize for future study are at variance with those that learners choose. Because teachers are presumed to have a greater knowledge or intuition of factors such as valency, range and frequency, it is crucial that awareness of such qualities be a salient factor when choosing texts for teaching purposes or when making teaching materials. Teachers should also attempt to impart this knowledge to learners in order to help them make more informed choices by themselves. Learners should not be left to their own lexical devices.

Any success in trying to get learners to master an adequate minimal vocabulary will be largely determined by the type of items that are included, not just their relative frequency (Lewis, 1993). Yet, the limited results of this study also indicated that several lexical categories and features considered central by scholars are often ignored by both teachers and learners. For example, Sinclair and Renouf (1988) argue that discourse markers or items containing pragmatic force, items which carry out the functions of a text, tend to be overlooked by most teachers. This 
fact too was borne out in this study as we noted that function words, general words, items which have largely interpersonal functions, lexically-light items plus items that have high recognition value but wide range and valency all tend to be under emphasized.

We also noted how the teachers surveyed here tended to overlook features of the text that were of considerable interest to English majors. Thus, it can be suggested that greater teacher awareness of and sensitivity to such items that appear simple by virtue of their individual constituents, yet are confusing to learners due to their wide meaning range or loss of density when appropriated as a lexical unit, are needed. A deeper understanding of the learners' L1, as well as an increase in teachers' understanding of the functions of lexis, may be ways of achieving this.

Finally, from these exploratory results, it can be suggested that learner interaction with a text alone does little to influence or guide learners' uninformed choices. Rather, explicit explanation by teachers appears to lead some students to make more informed selections, often by stimulating or challenging students' internal lexicons.

However, the fact that students tend to take a semasiological (wordto-thing) approach to definition, and avoid nomination (the type of definition that flows from thing to word) indicates that they often attempt to acquire lexis out of context, as if the assertion that "words have meanings" were a canonical fact of language. Rather, imparting an understanding that, in fact, it is meanings that have words would likely increase learners' sensitivity to lexical environments. Discrete explanations of "difficult" items alone are insufficient. Rather, tasks that illuminate context and provide frameworks of meaning are indispensable for any in-depth lexical analysis by learners (Willis, 1990).

\section{Conclusion}

Although extremely limited and exploratory, this study nonetheless suggests important directions for future research. The results indicate that, in order to develop learners' lexical skills, the choice of lexical items for analysis or study should not be left up to the individual learner, but rather deliberately and explicitly guided and monitored by teachers. Furthermore, teachers must also become more aware of the varied roles and functions of lexis, and in doing so separate it from the more limited category of "vocabulary." In moving towards a more lexically-based syllabus, both teachers and learners can become more aware of how lexis interacts with its linguistic environment, serves interpersonal and social functions, enables structures to cohese/cohere and provides signals for understanding the force of utterances. By becoming more aware 
of and ultimately being able to impart the centrality of lexis, teachers will be providing learners with tools that will serve as a strong foundation for almost any dimension of second language acquisition.

Michael Guest is a lecturer in English at Miyazaki Medical College. He is particularly interested in the patterns of spoken language, both grammatical and lexical.

\section{References}

Arnaud, P. J. L., \& Savignon, S. (1997). Rare words, complex lexical units and the advanced learner. In J. Coady \& T. Huckin (Eds.), Second language vocabulary acquisition (pp. 157-173). Cambridge: Cambridge University Press.

Carter, R. (1987). Vocabulary. London: Routledge.

Carter, R., \& McCarthy, M. (1994). Grammar and the spoken language. Applied Linguistics, 16(2), 141-157.

Fasold, R. (1990). The sociolinguistics of language. Oxford: Blackwell.

Francis, G. (1985). Anaphoric nouns. Discourse Analysis Monographs, 11. English Language Research, University of Birmingham.

Fukuda, T. (1994). The role of vocabulary notebooks in the EFL classroom in Japan. Hokkaido University Monographs. English Research, 25, 87-98.

Halliday, M. A. K. (1990). Spoken and written language. Oxford: Oxford University Press.

Halliday, M. A. K., \& Hasan, R. (1976). Cohesion in English. London: Longman.

Lewis, M. (1993). The lexical approach. London: The Language Teaching Press.

McCarthy, M. (1991). Discourse analysis for language teachers. Cambridge: Cambridge University Press.

McCarthy, M., \& Carter, R. (1995). Spoken grammar: What is it and how can we teach it? ELT Journal, 49 (3), 207-218.

Nattinger, J., \& DeCarrico, J. S. (1992). Lexical phrases and language teaching. Oxford: Oxford University Press.

Nunan, D. (1989). Designing tasks for the communicative classroom. Cambridge: Cambridge University Press.

Pawley, A., \& Syder, F. (1983). Two puzzles for linguistic theory: Nativelike selection and nativelike fluency. In J. Richards \& R. Schmidt (Eds.), Language and communication (pp. 191-227). London: Longman.

Quirk, R., Greenbaum, S., Leech, G., \& Svartvik, J. (1985). A comprehensive grammar of the English language. New York: Longman.

Richards, J. (1974). Word lists: Problems and prospects. RELC Journal, 5 (2), 69-84. Schiffrin, D. (1987). Discourse markers. Cambridge: Cambridge University Press.

Sinclair, J. (1991). Corpus concordance collocation. Oxford: Oxford University Press. Sinclair, J., \& Renouf, A. (1988). A lexical syllabus for language teaching. In R. Carter \& M. McCarthy (Eds.), Vocabulary and language teaching (pp. 140-160). New York: Longman.

Swain, M. (1995). Three functions of output in second language learning. In G. Cook \& S. Seidlhofer (Eds.), Principle and practice in applied linguistics. Oxford: Oxford University Press.

Swan, M. (1995). Practical English usage. Oxford: Oxford University Press. 
Ure, J. (1971) Lexical density and variety differentiation. In G. Perren \& J. Trim (Eds.), Applications of linguistics: Papers from the 2nd AlLA Congress (pp. 443452). Cambridge: Cambridge University Press.

Willis, D. (1990). The lexical syllabus. London: Collins Cobuild.

(Received September 9, 1998; revised August 30, 1999) 